\title{
SMART CITY BUS MOBILE APPLICATION
}

\author{
Enis AYTAR ${ }^{1}$, Serkan MEZARCIÖZ ${ }^{1}$, Murat DEMiRDÜZEN ${ }^{1}$, Mert \\ ÖZKAYNAK ${ }^{1}$, Kadir AYDIN ${ }^{2}$ \\ ${ }^{1}$ Temsa Global San. Ve Tic A.Ş. R\&D Center \\ ${ }^{2}$ University Of Cukurova, Department Of Automotive Engineering
}

Abstract. In the current study, a special mobile application was designed for the use of drivers, fleet managers and passengers of a smart city bus.

In the driver section of the application, some properties of smart city bus can be controlled via mobile application. Driver can start/stop the vehicle, control the $\mathrm{A} / \mathrm{C}$ system, preheater, lights, doors, horn etc of the bus by using this mobile application.

In the fleet manager section, some of important vehicle parameters, like instantaneous/average fuel consumption, engine speed, vehicle speed, engine coolant temperature, brake lining thickness, fuel level in the tank, all error codes for engine, transmission, brake or any other system in the bus etc can be monitored by fleet manager via mobile application.

In the Passenger section of the application, passengers can see estimated time of arrival for their station with the rate of fullness and real time position of the bus supplied by GPS. If passenger is inside the vehicle, passenger can connect to the media archive of the vehicle with Wi-Fi and watch videos or listen music.

In the current study, system components, and software details of the application were discussed and explained.

Keywords: Smart city transportation, Mobile application, Wi-Fi, Remote control, GPS, Fleet management. 

AYDIN

\section{INTRODUCTION}

Smart City is a recent topic, but it is spreading very fast, as it is perceived like a winning strategy to cope with some severe urban problems such as traffic, pollution, energy consumption, waste treatment. A Smart City is a complex, long-term vision of a better urban area, aiming at reducing its environmental footprint and at creating better quality of life for citizens. Mobility is one of the most difficult topic to face in metropolitan large areas. It involves both environmental and economic aspects, and needs both high Technologies and virtuous people behaviours. Smart Mobility is largely permeated by Information and Communication Technologies (ICT), used in both backward and forward applications, to support the optimization of traffic fluxes, but also to collect citizens' opinions about liveability in cities or quality of local public transport services [1].

Smart City is considered like a winning urban strategy using technology to increase the quality of life in urban space, both improving the environmental quality and delivering better services to the citizens [2].

\section{MATERIAL AND METHOD}

The system consists of mobile application, Wi-Fi communication, telemetry device, GPS, vehicle CAN BUS line, body controller, multiplexer and smart city bus as shown below in Figure 1. Telemetry device is connected to vehicle CAN BUS line and obtain CAN messages via its transreceiver. Obtained messages are evaluated with its Linux based processor according to SAE J1939-71 standard. Then telemetry device send CAN messages to mobile application via Wi-Fi communication. Telemetry device has GPS connection for location information and Wi-Fi feature to communicate with mobile application. 


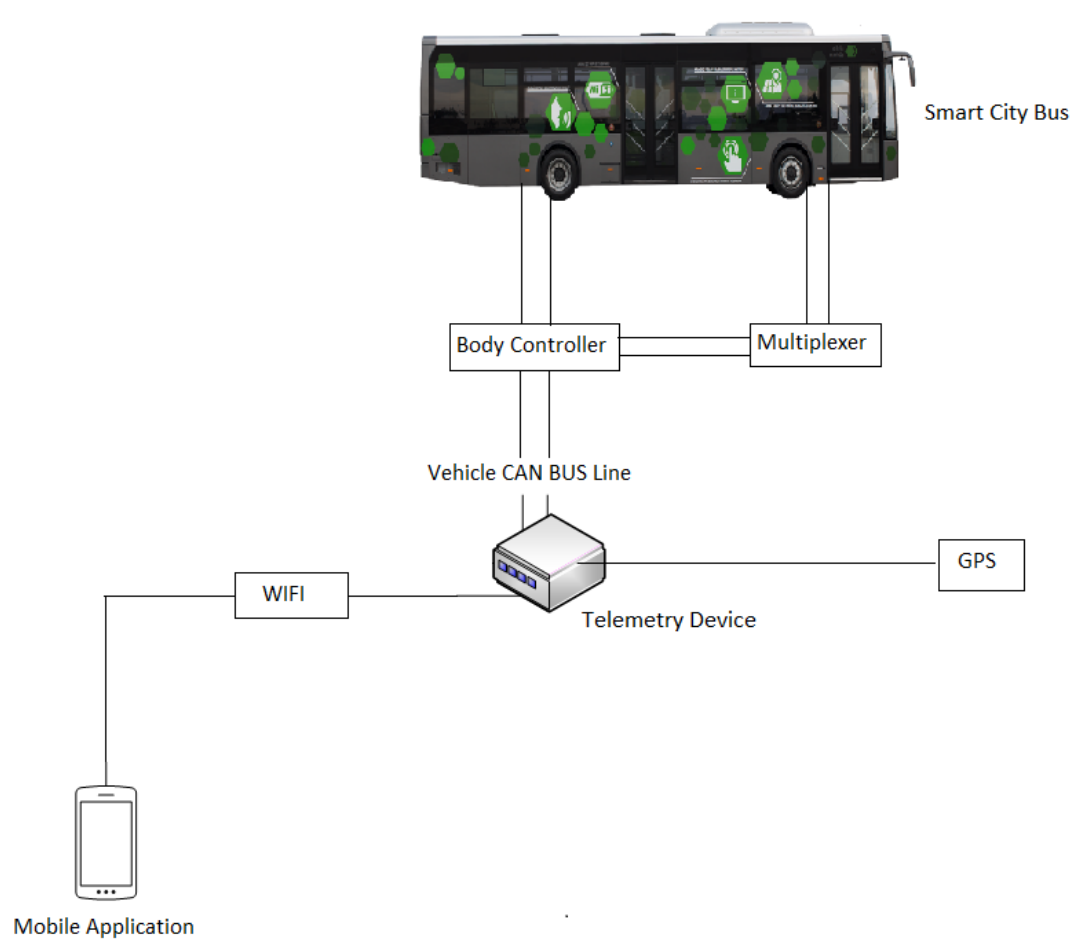

Fig. 1. General overview of the mobile application system

Mobile application send a command by its application buttons or voice control feature, telemetry device process this command and send a CAN message to body controller of the smart city bus. Body controller evaluates this message, send command to activate or deactivate multiplexer outputs for vehicle functions. The driver can turn on/off park lamps, low beams, high beams, fog lamps, interior lamps, left signals, right signals; open/close front, middle and rear doors; activate/deactivate kneeling, lifting and side kneeling; control horn, air conditioner, preheater; start/stop the engine etc. by using this mobile application. These functions can be customized according to customer demands. Some sample screenshots from driver section of the mobile application can be seen in Figure 2. 
4 Enis AYTAR, Serkan MEZARCIÖZ, Murat DEMIRDÜZEN, Mert ÖZKAYNAK, Kadir AYDIN

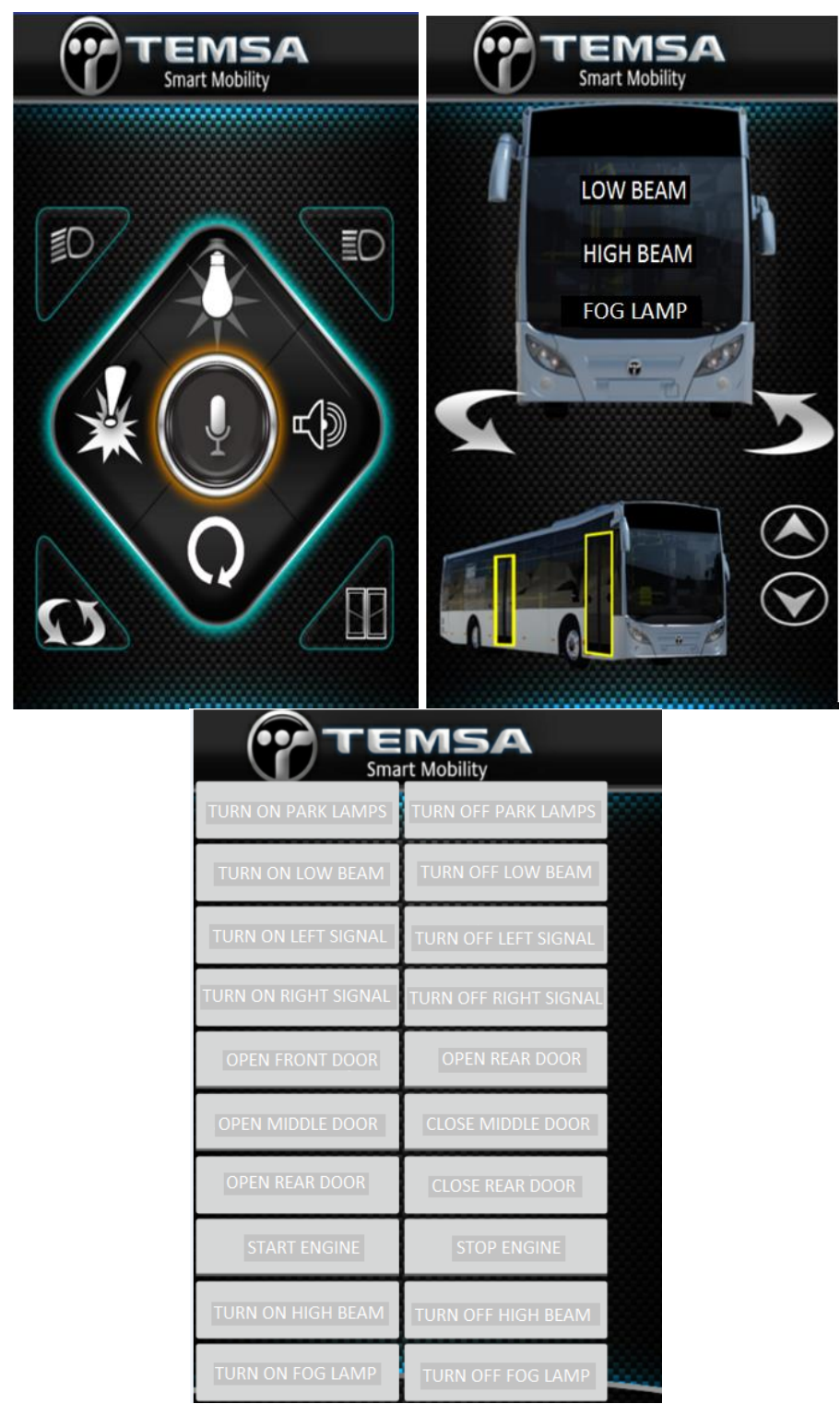

Fig. 2. Sample screenshots from driver section of the mobile application

In the fleet manager section, some of important vehicle parameters, like engine speed, vehicle speed, throttle pedal position, engine coolant temperature, front/rear brake tank pressure, park brake status, brake lining thickness, fuel level, instantaneous/average fuel consumption, total distance, battery voltage, adblue level, 
engine oil level, engine coolant level, remaining $\mathrm{km}$ for maintenance, failure status for engine, transmission, brake and suspension systems etc. can be monitored by fleet manager via mobile application. These messages can be customized according to customer demands.

Fleet managers or garage technicians don't have to go each vehicle to check fuel level, adblue level, engine coolant level, engine oil level, battery voltage etc. They can control all these parameters in their offices via mobile application. They also don't have to go each vehicle before its route to check if the vehicle has any error or not. They can connect to the vehicle and check the errors. Intercity drivers can also use this feature during their break. They can control fuel level, adblue level, engine oil level, engine coolant level etc. via mobile application. Mobile dashboard and vehicle status pages of the application can be seen in Figure 3.

In the passenger section of the application, passengers can see estimated time of arrival for their station with the rate of fullness and real time position of the bus supplied by GPS. Passengers can organize their travel according to these data and minimize the time lost during city transportation. If passenger is inside the vehicle, passenger can connect to the media archive of the vehicle with Wi-Fi and watch videos or listen to music, which are already stored in the vehicle computer. 
6 Enis AYTAR, Serkan MEZARCIÖZ, Murat DEMIRDÜZEN, Mert ÖZKAYNAK, Kadir AYDIN

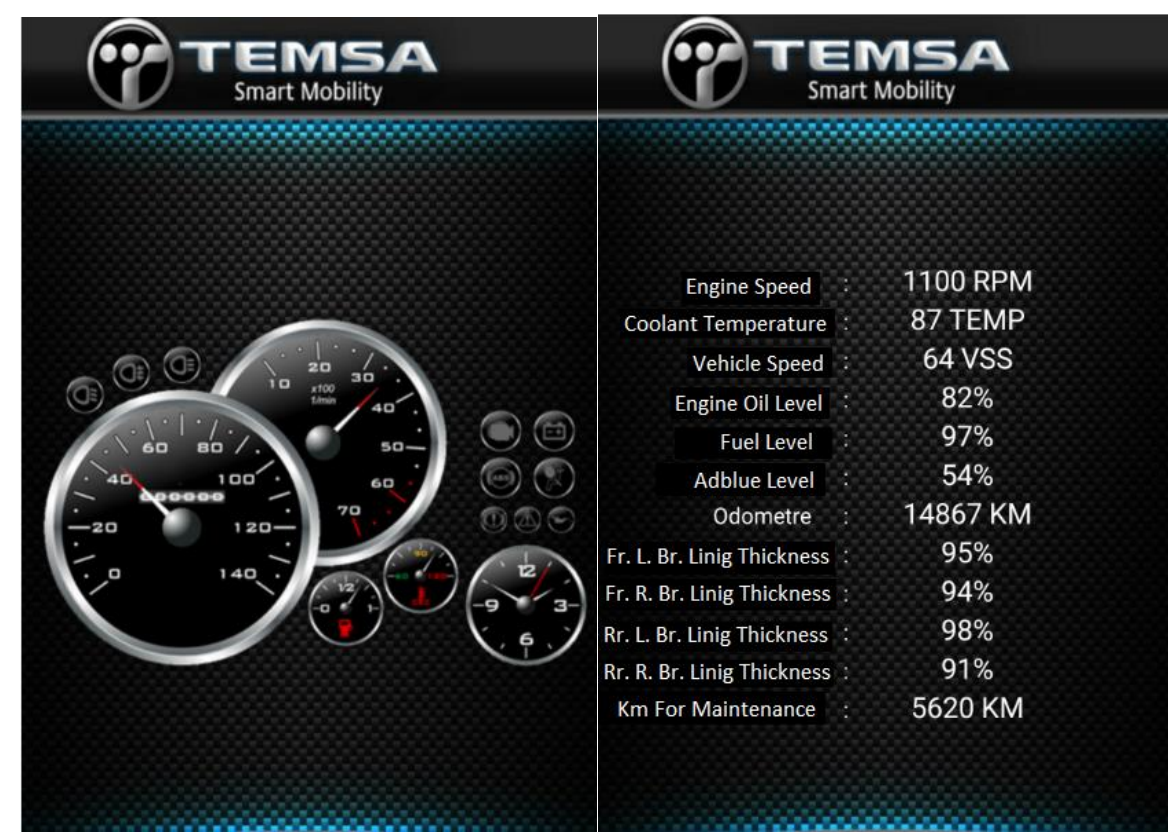

Fig. 3. Mobile dashboard and vehicle status pages of the application

\section{CONCLUSSION}

We present to control desired vehicle functions remotely to drivers and fleet managers. They can start the engine and turn on $\mathrm{A} / \mathrm{C}$ or preheater without going to the vehicle. Responsible people can activate necessary functions and can control from outside to see if it works or not by mobile application such as low beam, high beam, left/right signals, exterior lights etc. Fleet managers or garage technicians don't have to go each vehicle to check vehicle liquids such as fuel, adblue, oil etc. or errors before its route. They can make all these controls remotely by this mobile application. Municipalities, owners and fleet managers can save too much money and time by using this mobile application. Intercity drivers can also use this feature during their break. They can control fuel level, adblue level, engine oil level, engine coolant level etc. via mobile application. Passengers can see estimated time of arrival for their station with the rate of fullness and they can organize their travel according to these 
data. The most important feature of this mobile application is customization property according to customer demands.

\section{References}

[1]. Benevolo, C., Dameri, R. P., and D'Auria, B.,2016, Smart Mobility in Smart City Action Taxonomy, ICT Intensity and Public Benefits, Lecture Notes in Information Systems and Organisation, pp.17.

[2]. Hall, P., 2000, Creative cities and economic development. Urban Stud. 37, 633-649. 